\title{
The Development of Hypermedia Based E-Book for Integral Calculus Subject
}

\author{
https://doi.org/10.3991/ijoe.v16i04.13393
}

\author{
Awaludin ${ }^{(凶)}$, Basuki Wibawa, Murni Winarsih \\ Universitas Negeri Jakarta (UNJ), East Jakarta, Indonesia \\ awaludinrahman2016@gmail.com
}

\begin{abstract}
This research focuses on the development and the validity of hypermedia-based e-book for integral calculus subject. The research questions to be addressed are (1) how is the development of hypermedia-based e-book for integral calculus? (2) how is the feasibility level of hypermedia-based e-book for integral calculus subject? (3) is hypermedia-based e-book effective in improving integral calculus learning achievement? The objectives of the study are (1) to find out the process of developing hypermedia-based e-book for integral calculus class, (2) to determine the level of feasibility of hypermedia-based ebook for integral calculus class, (3) to find out the effectiveness of hypermedia based e-book used at integral calculus class. The research method employed was a research and development (R \& D) based on Lee and Owens model. The subjects of this research included a design expert, a media expert, a mathematics expert and students at mathematics department at Halu Oleo University. The data collected through questionnaire, interview and a test. The data then were analyzed using both descriptive and inferential statistics. The findings revealed that (1) the development of hypermedia based e-book using Lee and Owen model consists of need assessment, front-end analysis, development, implementation and evaluation, (2) hypermedia based e-book was feasible to be used at integral calculus class after being tested formatively, (3) the use of hypermedia based e-book was effective to improve students' integral calculus learning achievement.
\end{abstract}

Keywords - e-Book; Hypermedia; Lee, Owen Model

\section{Introduction}

E-book is the digital form or electronic form of a book which integrates various multimedia components such as text, image, audio, video and animation that can be accessed via computer or mobile phone [1]. The utilization of e-book as learning source nowadays has become unavoidable considering the simple form of e-book which enables the electronic file storing and access and through mobile phone or a note book. E-book can take different formats like PDF, EPUB, HTML, JPEG, ibook, JAVA SCRIPT and others. E-book in the form of PDF enables the integration of text, image, audio, video and animation. E-book in PDF format can be supported by various types of annotations such as text notes, hypertext links, markup, file attachments, 
sound and movement. Users can find particular object directly using mouse or keyboard. PDF document can also take a form of an interactive media that the user himself inputs from other applications [2].

The integration of multimedia components in e-books is an interesting thing because it enables the reader or user to understand the concept of a topic. E-book which integrates multimedia components is generally called interactive e-book or hypermedia e-book. Hypermedia is the linking of several structured multimedia components such as text, audio, video and animation that enables a person to navigate [3][4][5].

Several researches have been conducted in regards to the utilization of e-book. for instance [6] who found that e-book has the nature of providing interactive instructional material such as bookmarks, quizzes, and interactive lab and exercises to assists learners. Zhang-kennedy et al.[7] reported that interactive e-book affected the acquisition, retention and transfer of knowledge and it plays a role in connecting prior knowledge with the new knowledge. Yildirim [8] stated that students learnt more effectively when using hypermedia material that based on their environment. Yildirim et al.[9] argued that the students' learning achievement using hypermedia ebook showed better result than traditional way.

In similar Gonźalez et al.[10] stated that interactive e-book makes it possible for texts to be linked with various multimedia components. Multimedia components include image, audio, video and animation. They further argue that developing interactive e-book can facilitate teachers and students in learning process. through interactive e-book, students can access text, image,audio, video and animation. Based on the research findings on the utilization of e-book in learning process, this article will discuss the development of hypermedia based e-book in integral calculus class. Hypermedia based e-book refers to the integration of various multimedia components such as image, audio, video and animation.

The use of multimedia components in developing e-book for integral calculus class is due to the subject nature of integral calculus which is abstract. Therefore, visualization through image, animation and video is needed to help students understand the subject material. The integration of multimedia elements in e-book has several advantages including:

1. Students can learn calculus anywhere and at anytime

2. e-book can be taken anywhere

3. e-book can be accessed through a mobile phone and a computer

4. Hypermedia based e-book enables students to understand calculus concepts like Riemann integral or interior and exteriror angle of polygon, calculation of volume of a solid from the curve.

Therefore, this article will discuss:

1. The development of hypermedia based e-book in integral calculus

2. The feasibility level of hypermedia based e-book in intergal calculus class

3. The effectiveness of hypermedia based ebook in improving students' integral calculus achievement. 


\subsection{The objectives of the study}

The objectives of this study are:

1. To develop hypermedia based e-book in integral calculus for mathematics department at Halu Oleo University

2. To find out the level of feasibility of hypermedia based e-book in integral calculus class of Mathematics department at Halu Oleo University

3. To find out the effectiveness of hypermedia based e-book in improving integral calculus learning achievement.

\section{Literature Review}

\section{$2.1 \quad$ Definition of e-book}

According to Figueiredo and Bidara, 2015: Çalışkan, and Demirci (Hakan, Hamit and Erbay, 2014, Laura Monica,et al, 2014 cited in [1], e-book is an electronic book which take on different forms like PDF, EPUB,i-Book that can integrate multimedia components such as image, audio, video and animation and enable learners to learn. E-book multimedia components are more interactive, dynamic and make the object studied become more tangible. Figueiredo and Bidarra, (2015); Hakan, Hamit dan Erbay, 2014; Laura Monica, et al, (2014), as cited in [11], e-book can be accessed through a computer or a mobile phone with the support of high resolution, compatible device which enables reader to access anywhere and anytime. Therefore, e-book is a digital form of printed book that integrates multimedia components such as image, audio, video and animation that can be accessed using a mobile phone or a computer and enables readers to understand the information provided in the e-book. E-book can be in the form of PDF, JPEG, EPUB, I-Book, and others which accessing e-book requires compatible application to enable the use of e-book.

\subsection{Hypermedia concept}

According to Roblyer and Doering, [4]; Vaughan (2011, as cited in Awaludin et al.[11] Hypermedia is the linking of several structured multimedia components that enable quick access through navigation system provided. Mishra and Sharma [3] and Vaughan (2011) stated that hypermedia is interlinking of various multimedia documents like texts, graphics, arts, sounds, animation and video sent through a computer or other electronic devices. Awaludin et al.[11] stated that hypermedia is a collection of multimedia documents that link one another and can be accessed through computer or hand phone. 


\subsection{Hypermedia based e-book}

According to Awaludin et al.[11], hypermedia based e-book is a digital form of a book that is designed based on the elements of learning model by incorporating various multiemedia components such as text, image, video, animation and hyperlink that are linked directly and are able to see and access using personal computer with PDF,HTML and JPEF,iBook, animation, video format. According to Elliot and Miller (1999 cited in Awaludin et al.[11] animation in e-book can be in the form of image or object that moves fast and orderly which showing the movement of a real object. Awaludin et al.[11] states that when students learn by looking at the real object, they find it easier to understand and comprehend concepts of the object. Students find it easier to visualize the object in their mind and make it last long in their memory.

Through video, students can learn the object's behavior directly through observation that helps developing the representation ability, cognitive-perceptual ability, and video can be used as guide in completing assignment[12][13][14]. The existence of multimedia components such as text, image, video and animation in ebook can increase students' learning motivation, participation and memory. Furthermore, these multimedia components can improve students' comprehension on the material being studied. This condition surely helps improving students learning achievement [11].

\section{$3 \quad$ Research Methods}

\subsection{Research design}

This research was a research and development (R\&D) and adapted a model by Lee and Owens which consisted of need assessment, front-end analysis, design, development and implementation and evaluation.

\subsection{Research procedure}

The research procedures consist of need analysis. This phase is called need assessment which is a systematic way to determine the existing gap between the real condition and the expeced condition. Furthermore, need assessment is also a systematic process in determining goals, identifying discrepencies between the actual condition and the expected condition and developing priorities for action.

Front-end analysis is a technique of data collection that is used to bridge the gap exist by determining the solution needed. The types of front-end analysis include:

1. Audience analyis

2. Technology analysis

3. Task analysis

4. Critical-incident analysis

5. Situational analysis

6. Objective analysis 
1. Media analysis

2. Extant-data analysis

3. Cost-benefit analysis.

Design is a planning phase of multimedia project. Planning is an important factor for a successful process of creating multimedia. The result of this phase is a course design specification (CDS). To create CDS, some actions are needed to be done namely:

1. Determine the media specification to be used including e-book document format, media components such as text, image, video and animation, language structure, delivery style, font size and type and other aspects. At this stage, everything is based on the delivery theory of multimedia/hypermedia elements of an e-book

2. Determine the specification and structure of lesson including the content that is groupped and linked

3. Configuration control and review cycle which is the way the media elements are designed and managed, and document is reviewed.

The development and implementation phase inlcude developing and implementing the specification design applied. Evaluation phase is done to the four aspects of arrangement strategy evaluation, developing plan evaluation, developing accurate instrument, and applying instrument evaluation and analyzing evaluation result. The advantages of this model are:

1. Having a detailed development phase

2. Lee and Owens model is a model that is designed and developed for multimedia based instruction.

In brief, the phases of Lee and Owens model are presented in Table 1.

\subsection{Student's Activity in The research subject and informant}

The subject of this research was the 2017/2018 students of mathematics department at Halu Oleo university comprising of students who had taken integral calculus class and students who are taking integral calculus class. The informants were a design expert, a media expert and two mathemathics experts.

\subsection{Technique of data collection}

The data were gathered using two instruments namely non-test and test. Non test inlcudes interview guidelines and questionnaire. Test includes item test of integral calculus that had been validated by experts. The theoretical validity was done by experts and emipirical validity was done by try-out which then analyzed both its validity and reliability. The validitiy of item test was analyzed using the point biserial correlation while the reliability was measured using KR-21. 
Table 1. every Phases of Lee and Owen Model

\begin{tabular}{|c|c|c|}
\hline Phase & Activity & Outcomes \\
\hline Need Assessment & \begin{tabular}{|l|} 
Determine the students' competence in \\
calculus class \\
Determine the expected competence to \\
be achieved after learning integral calcu- \\
lus \\
Illustrate integral calculus lesson
\end{tabular} & $\begin{array}{l}\text { Students' competence profile in learning } \\
\text { integral calculus } \\
\text { General objectives of calculus lesson } \\
\text { Illustration of teaching and learning process } \\
\text { of integral calculus }\end{array}$ \\
\hline Front-end analysis & $\begin{array}{l}\text { Audience analysis } \\
\text { Technology analysis } \\
\text { Assignment analysis } \\
\text { Critical incident analysis } \\
\text { Situation analysis } \\
\text { Goals analysis } \\
\text { Media analysis } \\
\text { Extant data analysis }\end{array}$ & $\begin{array}{l}\text { Students' characteristics } \\
\text { Available technology source } \\
\text { Illustration of status, obligation and task for } \\
\text { students to be completed } \\
\text { Profile of students' knowledge and skill } \\
\text { Illustration of learning environment } \\
\text { Instructional objectives } \\
\text { Media specification used } \\
\text { Hypermedia based e-book learning material }\end{array}$ \\
\hline Design & \begin{tabular}{|l|} 
Determine media specification \\
Determine specification and content of \\
learning material \\
Design media elements and managed and \\
review document
\end{tabular} & E-book format used \\
\hline $\begin{array}{l}\text { Development and } \\
\text { implementation }\end{array}$ & & \begin{tabular}{|l|} 
Draft of hypermedia-based e-book \\
Validity result of hypermedia-based e-book
\end{tabular} \\
\hline Evaluation & $\begin{array}{l}\text { Determine the evaluation domain } \\
\text { Arrange the evaluation instrument } \\
\text { Validate the evaluation instrument } \\
\text { Conduct the evaluation }\end{array}$ & $\begin{array}{l}\text { Evaluate the effectiveness of hypermedia- } \\
\text { based e-book on students' integral calculus } \\
\text { learning achievement }\end{array}$ \\
\hline
\end{tabular}

\subsection{Technique of data analysis}

The data were analyzed using descriptive and inferential statistics. The descriptive analysis consists of the average score of normal gain (N-gain) from pre-test nda posttest score, maximum and minimum scores and standard deviation. Inferential analysis consists of normality test of $\mathrm{N}$-gain and one sample t-test to test the improvement of students' integral calculus learning achievement.

\section{$4 \quad$ Result}

The result of this development of hypermedia based ebook research is divided into two parts namely description of result of hypermedia based ebook in integral calculus class and description of feasibility test on development of hypermedia based ebook for integral calculus class.

\subsection{The development of hypermedia-based e-book}

Need assessment: Hypermedia based ebook in integral calculus class was designed based on the phases in Lee and Owens model which consisted of need assessment, front-end analysis,design, development and implementation and evaluation. Need 
assessment is conducted to determine the students' competence in calculus and the expected competence to be achieved after learning integral calculus lesson. The data on students' competence is collected through questionnaire and interview. Need assessment is done to the students who have taken integral calculus class. Based on the questionnaire result, it is found that students' competence in calculus are still low. The data are gathered from the students and the lecturer in charge of integral calculus class. The following table shows the student's competence in integral calculus class.

Table 2. Student's Competence in Integral Calculus Class

\begin{tabular}{|c|l|c|c|c|c|}
\hline \multirow{2}{*}{ Number } & \multicolumn{1}{|c|}{ Competence } & \multicolumn{3}{c|}{ \% outcomes } \\
\cline { 3 - 5 } & & 1 & 2 & 3 & 4 \\
\hline 1 & Determine the antiderivative of a function & 11.5 & 26.9 & 46.2 & 15.4 \\
\hline 2 & Use integral rules (antiderivative) & 19.2 & 34.6 & 30.8 & 15.4 \\
\hline 3 & Determine the solution of a differential equation & 53.9 & 30.8 & 7.6 & 7.6 \\
\hline 4 & Use sigma notation & 46.1 & 23.1 & 15.4 & 15.4 \\
\hline 5 & $\begin{array}{l}\text { Determine the area with polygon approach namely interior angle and } \\
\text { exterior angle }\end{array}$ & 61.5 & 19.2 & 11.5 & 7.7 \\
\hline 6 & Calculate the Riemann sum of a function in a partition with interval & 46.2 & 19.2 & 23.0 & 11.5 \\
\hline 7 & Use the first fundamental theorem of calculus to solve a problem & 42.3 & 23.1 & 23.1 & 11.5 \\
\hline 8 & $\begin{array}{l}\text { Use the second fundamental theorem of calculus to solve definite } \\
\text { integral problem }\end{array}$ & 46.2 & 19.2 & 26.9 & 26.9 \\
\hline 9 & Determine the average value of a function of definite interval & 34.6 & 34.6 & 26.9 & 3.85 \\
\hline 10 & Use substitution method & 53.8 & 19.2 & 15.4 & 11.5 \\
\hline 11 & Determine the value of definite integral using symmetry function & 53.8 & 19.2 & 19.2 & 7.7 \\
\hline 12 & Determine the value of definite integral using periodic function & 50.0 & 19.2 & 26.9 & 3.8 \\
\hline 13 & Determine width of an area above and below x axis & 53.9 & 26.9 & 11.5 & 7.7 \\
\hline 14 & Determine the area of two curves using definite integral & 53.9 & 26.9 & 11.5 & 7.7 \\
\hline 15 & Determine the volume of a solid using disc method & 57.7 & 23.1 & 11.5 & 7.7 \\
\hline 16 & Determine the volume of a solid using shell method & 53.8 & 23.1 & 19.2 & 3.9 \\
\hline
\end{tabular}

Meanwhile, the questionnaire result given to the lecturer in charge of integral calculus class showed that students' ability in integral calculus were still low. Table 3 illustrates the level of students' ability.

The average score of students' integral calculus test was 56.6. This is clearly still far from the expected average score which is 65 . Based on the illustration of students' competences collected from the students and the leturer, it reveals that the students' competences in integral calculus are are still relatively low. However, the students studying at mathematics department are expected to have the competence of integral mastery to study advanced mathematics.

The illustration on students' competence in integral calculus subject in need assessment phase showed low level of competence. Out of sixteen basic competences to be mastered

1. Two competences are categorized good namely writing the definition of derivative and determining antiderivative (definite integral)

2. Two competences are categorized medium namely using antiderivative and sigma notation,

3. Twelve competences are categorized low. 
Table 3. Level of Student's Ability in Integral Calculus

\begin{tabular}{|c|c|c|c|c|c|c|}
\hline \multirow{2}{*}{ Number } & \multirow{2}{*}{ Competences } & \multicolumn{4}{|c|}{ Score } & \multirow{2}{*}{ Status } \\
\hline & & 4 & 3 & 2 & 1 & \\
\hline 1 & Determine the antiderivative of a function & & & $\sqrt{ }$ & & Medium \\
\hline 2 & Determine integral rules (antiderivative) & & & $\sqrt{ }$ & & Medium \\
\hline 3 & Determine the solution of a differential equation & & & & $\sqrt{ }$ & Low \\
\hline 4 & Use sigma notation & & & & $\sqrt{ }$ & Low \\
\hline 5 & $\begin{array}{l}\text { Determine the area with polygon approach namely interior angle } \\
\text { and exterior angle }\end{array}$ & & & & $\sqrt{ }$ & Low \\
\hline 6 & Calculate the Riemann sum of a function in a partition with interval & & & & $\sqrt{ }$ & Low \\
\hline 7 & Use the first fundamental theorem of calculus to solve problem & & & & $\sqrt{ }$ & Low \\
\hline 8 & $\begin{array}{l}\text { Use the second fundamental theorem of calculus to solve definite } \\
\text { integral problem }\end{array}$ & & & $\sqrt{ }$ & & Medium \\
\hline 9 & Determine the average value of a function of definite interval & & & & $\sqrt{ }$ & Low \\
\hline 10 & Use substitution method & & & & $\sqrt{ }$ & Low \\
\hline 11 & Determine the value of definite integral using symmetry function & & & & $\sqrt{ }$ & Low \\
\hline 12 & Determine the value of definite integral using periodic function & & & & $\sqrt{ }$ & Low \\
\hline 13 & Determine the area of a plane above and below $\mathrm{x}$ - axis & & & $\sqrt{ }$ & & Medium \\
\hline 14 & Determine the area of two curves using definite integral & & & & $\sqrt{ }$ & Low \\
\hline 15 & Determine the volume of a solid using disc method & & & & $\sqrt{ }$ & Low \\
\hline 16 & Determine the volume a solid using shell method & & & & $\sqrt{ }$ & Low \\
\hline
\end{tabular}

Meanwhile, based on the lecturer evaluation, it reveals that:

1) Four competences have been mastered well,

2) Twelve competences havent been mastered quite well.

According to the need analysis, it can be concluded that there is a gap in learning integral calculus. Therefore to solve the problems, front-end analysis is conducted.

Front-end analysis: Front-end analysis consists of audience analysis, technology analysis, assignment analysis, critical-incident analysis, goals analysis, extant-data analysis. Front-end analysis is conducted to bridge the gap between the students' competences and the expected competences to be achieved.

Audience analysis: Audience analysis is done to identify the learning characteristics and prerequisite competence of the students. Based on the research findings, the students' characteristics can be seen in the following table.

Table 4. Students' Characteristics

\begin{tabular}{|c|l|l|c|}
\hline Number & \multicolumn{1}{|c|}{ Students' Characteristics } & \multicolumn{1}{c|}{ Category } & Percentage (\%) \\
\hline 1 & Level of education & Senior High School (SMA) & 100 \\
\hline 2 & Have studied integral & Yes & 100 \\
\hline 3 & Experiencing difficulties in understanding integral & Generally, yes & 95 \\
\hline 4 & Attitude toward integral subject & Positive & 100 \\
\hline 5 & Motivation to study integral calculus & High & 100 \\
\hline 6 & Understand text & Easy & 95 \\
\hline 7 & Read graphic & Easy & 85 \\
\hline 8 & Understand information through video & Yes, easy to understand & 95 \\
\hline 9 & Understand information through animation & Yes, easy to understand & 95 \\
\hline
\end{tabular}


The majority of mathematics students were senior high school graduates and had studied integral concepts. However, they still found it difficult to understand integral concept. Nevertheless, they showed positive attitude and high motivation to study integral calculus. Moreover, students found it easy to read graphic, understand information through video and animation. In addition, the data from SIAKAD of academic year 2016/2017 showed that the passing percentage of integral calculus was $78.18 \%$.

Technology analysis: Technology analysis is conducted to find out the availibility of technology to support the utilization of e-book as learning source. Based on the technology analysis, mathematics department, Halu Oleo University has a computer laboratory. Besides, students own their own computers like PC or notebook. They also can access the ebook via mobile phone.

Task analysis: Task analysis is breaking down the job into duties and task or in other words determining knowledge, skill and attitude to be achieved to work well. The steps to conduct task analysis include:

1. Determining position (role)

2. Deteriming all the duties (tasks) in regards to the work

3. Identifying all the tasks

4. Arranging the tasks

Students' expected job is to be mathematics teacher or teaching integral calculus. To do the job, the students have duties and task. Duties include to master the concept of indefinite integral and definite integral, implement the calculus concept in measuring the area of a plane, volume of a solid and other daily problem. Students' tasks are to explain the antiderivative concept, definite integral, sigma notation, the area of a square, measure the volume of a solid. The result of task analysis can be seen in the following figure:

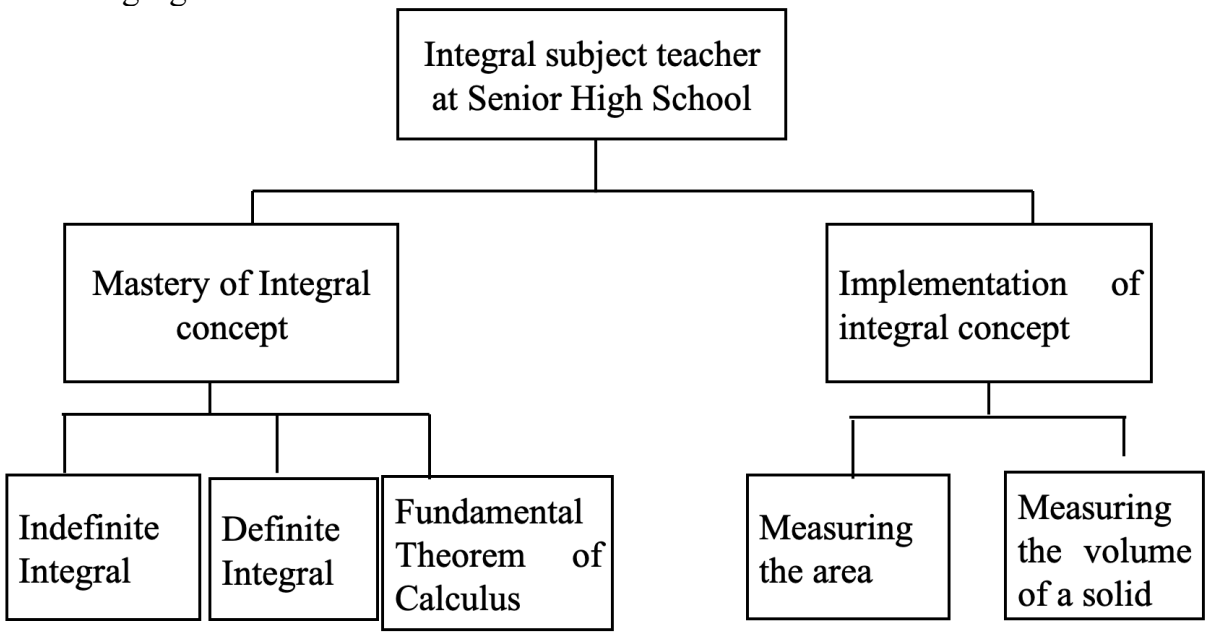

Fig. 1. Result of Task Analysis 
Critical Incident Analysis: In this phase, the knowledge and skills required are determined. This phase is conducted to find the tasks to be completed by students to achieve the learning acheivement based on the condition and pre-determined standard (Curriculum). The result of critical analysis becomes the foundation to determine the instructional objectives of integral calculus. The knowledge required includes determining indefinite integral of a fucntion, solving a definite integral problem, using fundamental theorem of calculus to solve integral and using definite integral concept to determine the area and volume of a solid.

Situational analysis: Situational analysis is done to identify the environment that affects the objectives and the design of multimedia product. Based on the observation on the environment of learning at Mathematics department, it is showed that learning environment is comfortable, far from noise, good lightning, good air circulation, classroom size of $7 \mathrm{~m} \times 12 \mathrm{~m}$. The classroom is equipped with LCD and Air Conditioning $(\mathrm{AC})$ to support and create comfortable situation during the process of teaching and learning

Goals analysis: Writing the specific instructional objectives to be achieved includes (1) determining the domain of specific isntructional objectives (cognitive, affetive and psychomotor), determining the level of each domain, (3) writing the general instructional objectives, and (4) writing the specific instructional objectives. The instructional objectives domain of integral calculus measured in this study is cognitive domain. The cognitive level consists of remembering, understanding, applying, analyzing, evaluating and creating.

General instructional objetives is " to master the integral calculus concept in learning and able to apply the concept in solving mathematics problems and daily problems". Meanwhile the specific instructional analysis of integral calculus are as follows : Upon completion of the integral calculus class, students are able to:

1. Determine the antiderivative of a function correctly if given a function

2. Use the integral rules (antiderivative) to solve problems correctly if given a problem

3. Determine a solution for a differential equation correcttly if given a differential equation

4. Use sigma notation correctly if given many substitution problems

5. Determine the area of under a curve using polygon method namely interior angle and exterior angle correctly if given a curve

6. Measure Riemann sum of a function in a partition with interval correctly if givena function and a partition

7. Create a mathematical model Riemann sum ( Rp) and determine the total area correctly if given a function $\mathrm{f}(\mathrm{x})$ of a partition in closed interval.

8. Draw a structured coordinate system, use an integral mdel using substitution and measure the area correctly

9. Use the first fundamental theorem of calculus to solve derivative problem of an integral correctly if given a problem

10. Use the second fundamental theorem of calculus to solve indefinite integral problem correctly if given a definite integral function 
11. Determine the average value of a fucntion in an definite interval correctly if given a function of specified interval

12. Use subtitution method to solve integral problem correctly if given an integral problem

13. Determine the value of definite integral using assymetric function correctly if given an integral problem

14. Determine the value of definite integral using periodic function correctly if given an integral problem

15. Determine the area of a plane above and below x-axis using definite integral correctly if given a function

16. Determine the area of a plane regions between two curves using definite integral correctly if given a function

17. Determine the volume of a solid using disc method and shell method correctly if given a curve $y=f(x)$

18. Determine the volume of a solid using shell method corretly if given a solid problem

Media Analysis: Based on the result of audience analysis, situational analysis and goals analysis, media will be used in integral calculus is hypermedia based ebook. The use of hypermedia ebook is considered because:

1. e-book is easier to be used

2. e-book is more interactive

3. e-book enables the learning of concepts of calculus

4. e-book enables the learning acitvity anywhere and anytime

5. e-book is more effective and efficient than printed book.

Exteant-data analysis: In this phase, the developer identifies the instructional material to be used. From the preliminiary study, it was found that the lecturer had made instructional material for integral calculus course. However, the material still needed some improvement. Moreover, it was also found that the use of the material were still unable to improve students' acheivement. Therefore, the developer identified the source and arranged a new instructional material. The references used in developing the material include text book or calculus ebook and also various videos on integral calculus subject.

Cost analysis: Cost analysis is done to identify the cost needed to develop a product. Considering that this is an academic activity not a business, cost analysis is not conducted.

Design: Design is a planning phase of multimedia project. Planning is an important factor for a successful process of creating multimedia. The result of this phase is a course design specification (CDS). To create CDS, some actions are needed to be done namely:

1. Determine the media specification to be used

2. Determine the specification and structure of lesson including the content that is groupped and linked 
3. Configuration control and review cycle which is the way the media elements are designed and managed, and document is reviewed. The media specification includes types of document, delivery style, text, language structure, graphic, font, theme, symbols edit and others

4. Lesson structure which describes how the content is groupped, arranged and linked. The instructional material is arranged based on the instructional activity. instructional activity includes unit topic, sub unit topic and content in detail to be written in story board. Moreover, feedback, user control which use interactively, test

5. Configuration Control and Review Cycle is the way the media components are designed and managed. Also, the documents are reviewed.

Hypermedia based e-book design produced a specification and content structure of the hypermedia e-book. Based on the media analysis result, the specification and content structure of the hypermedia e-book for integral calculus designed using PDF format to link text, image, video and animation. PDF format can be accessed through a computer like note book or personal computer (PC) and also mobile phones. However, some mobile phones cannot access or are not compatible with video and animation. The use of PDF format in developing hypermedia-based e-book is due its easy access nature using Adobe Flash and it can be linked with image, inter text, video and animation. The size of animation and video in e-book is relatively low which enables access.

Multimedia design like image, animation and video are in accordance with learning theories and utilization of media in instructional process. Image is integrated in ebook in the form of visualization of a concept. Video used is integral calculus instructional video focusing on the making of theorem. Animation presented is animation in measuring area of a solid using interior and exterior angle of polygon, measure the area below a curve using interior and exterior angle, animation on measuring the area under a curve using Riemann sum, animation on the rotation of a curve circling $\mathrm{x}$ axis and $y$ axis as a visualization of measuring the volume of a solid.

The content structure of hypermedia-based e-book uses the structure of development of text book based on the current curriculum. This means the content consists of front and back cover, front page e-book, content of e-book and ending part of hypermedia-based e-book. 
Table 5. Content Structure of Hypermedia Based E-Book

\begin{tabular}{|c|c|c|}
\hline Number & Hypermedia based ebook components & Specification \\
\hline 1 & Units & $\begin{array}{l}\text { Antiderivative } \\
\text { Fundamental theorem of calculus } \\
\text { Applying Integral }\end{array}$ \\
\hline 2 & Front cover page E-Book & $\begin{array}{l}\text { Cover color: Blue Denim } \\
\text { Title: Integral Calculus hypermedia based } \\
\text { Title color: Yellow (Segoe UI Black, font 74) } \\
\text { Font type for author's name: Arial } \\
\text { Font size for author's name: Font } 30 \\
\text { Author's name color: Yellow } \\
\text { Image in cover page: Stars and fireworks } \\
\text { View: Portrait } \\
\text { Ebook size: A4 } \\
\text { Publisher and Logo: } \\
\text { Cover page color: } \\
\text { Image at the back-cover page: blue } \\
\text { Image color: - } \\
\text { Size and font of synopsis: Arial } 20 \\
\text { Paper size: A4 } \\
\text { Publisher }\end{array}$ \\
\hline 3 & $\begin{array}{l}\text { Front part of the book } \\
\text { Title page } \\
\text { Main title page } \\
\text { Copyright page } \\
\text { Preface page } \\
\text { How-to-use page } \\
\text { Content list page }\end{array}$ & $\begin{array}{l}\text { Book title and start button to content list on the } \\
\text { middle right }\end{array}$ \\
\hline 4 & Content & $\begin{array}{l}\text { Chapter title or topic units } \\
\text { Brief description of the unit content } \\
\text { Explanation on chapter objective } \\
\text { Explanation on the theories } \\
\text { Examples } \\
\text { Summary } \\
\text { Exercises }\end{array}$ \\
\hline 5 & Ending Part & \begin{tabular}{|l|} 
Glossary \\
Index \\
Answer Key \\
References
\end{tabular} \\
\hline
\end{tabular}

Development and implementation: The development of hypermedia based ebook is done in several stages. The stages inlcude:

1. Arrange the e-book material

2. Create hypermedia components like image, animation an video

3. Integrate hypermedia components into e-book

4. Conduct formative evaluation

5. Implement hypermedia based e-book in integral calculus class.

Hypermedia based e-book material in integral calculus is based on the instructional objectives to be achived, content structure and instructional strategy designed for integral calculus instruction. The arrangement of hypermedia based e-book material in integral calculus class covers concept, principles and facts. The hypermedia 
components included in the e-book are animation, video, image and audio. These elements are integrated in the e-book to enable formative evaluation on hypermedia based e-book.

Formative evaluation is conducted to find out the feasibility of hypermedia based e-book that has been developed. Formative evaluation of hypermedia based e-book includes one-to-one evaluation by expert, one-to-one evaluation by students, implementation in small group, implementation and evaluation in large group. Evaluation of hypermedia based e-book involves media expert, design expert and mathematics instruction expert.

Expert evaluation:

Table 6. Expert Evaluation

\begin{tabular}{|c|c|c|c|}
\hline Validator & Evaluation Components & Aspects of Evaluation & Result (\%) \\
\hline \multirow[t]{6}{*}{ Media Expert } & \multirow[t]{5}{*}{ Media } & E-book look & 93.3 \\
\hline & & E-book size & 73 \\
\hline & & E-book composition & 93.3 \\
\hline & & Hypermedia usability & 93.3 \\
\hline & & Program Application & 95.5 \\
\hline & \multicolumn{2}{|l|}{ Average Value } & 89.68 \\
\hline \multirow{4}{*}{$\begin{array}{l}\text { Instructional design } \\
\text { expert }\end{array}$} & \multirow[t]{3}{*}{ E-book design } & Formulating instructional objectives & 95 \\
\hline & & Strategy of material organization & 91.7 \\
\hline & & Strategy of material delivery & 93.8 \\
\hline & Average value & & 93.5 \\
\hline \multirow[t]{6}{*}{$\begin{array}{l}\text { Mathematics } \\
\text { Instruction expert }\end{array}$} & \multirow[t]{5}{*}{ Instructional Material } & $\begin{array}{l}\text { Conformity between material and } \\
\text { objectives }\end{array}$ & 90 \\
\hline & & Material accuracy & 85.7 \\
\hline & & Language use & 86 \\
\hline & & Material organization & 97.5 \\
\hline & & Assessment & 92 \\
\hline & Average value & & 90.24 \\
\hline
\end{tabular}

Based on the above table, it can be seen that the result of validity by media expert shows e-book outlook is $93.3 \%$, ebook size is $73 \%$, ebook composition is $93.3 \%$, hypermedia usability is $93.3 \%$ and program application is $95.5 \%$ with average value of $89.68 \%$ and categorized as very good. Then the validity result by instructional design expert shows formulation instructional objectives reaches 95\%, material organization strategy reaches $91.7 \%$, material delivery strategy reaches $93.8 \%$. Therefore, it can be interpreted that e-book design is categorized very good reaching $93.5 \%$

Meanwhile the result of mathematics instruction experts shows that conformity between material and objective is $90 \%$, material accuracy is $85.7 \%$, language use is $86 \%$, material organization is $97.5 \%$ and assessment is $92 \%$. It can be concluded that hypermedia based e-book as instructional material is categorized very good reaching $90.24 \%$.

One to one Evaluation by Students: One-to-one evaluation by students of hypermedia based ebook involves three students with high, medium and low abilities. 
These students were given the hypermedia ebook drafts that had been revised to gain the insights. The students were asked to read and study the drafts then give their comments through questionnaires. The result of students evaluation shows that the presentation quality is $85.8 \%$, hypermedia ebook material quality is $87.4 \%$ and ebook usability is $96.7 \%$. It can be concluded that hypermedia based ebook as instrustructional material is $89.9 \%$ and categorized very good.

Small group evaluation: Small group evaluation is conducted by filling the questionnaire. Ten students participated in this phase. The result of small group evaluation shows that instructional material in the form of hypermedia e-book for integral calculus class is $91.55 \%$ and categorized very good. The mastery ability of integral calculus prior to the instruction (pre-test) was $42.4 \%$ while the average value after the instruction (post-test)was $72.8 \%$. This indicates that there is an improvement on students' learning acheivement after the use of hypermedia based ebook as instrucational material.

Field Try: The field try is done to find the effectiveness of hypermedia ebook as instructional material in achieving the expected objectives and the user responses on the product. The effectiveness of the product is gained through the users' responses during the field test and the test result of hypermedia based e-book as instructional material. The result of questionnaire filled out by thirty students showes that hypermedia based ebook as instructional material is $94.11 \%$ and categorized very good.

Evaluation: Evaluation is conducted to find the effectiveness of hypermedia based ebook on the improvement of students' integral calculus achevement. Evaluation is done through pre-test and post-test during the field try. Evaluation was conducted using multiple choice questions test. The data were analysed by calculating the gain score of pre-test and post-test which categorized normal ( $\mathrm{N}$-gain). The data were analyzed using descriptive and inferential analysis. The result of descriptive analysis of N-gain before and after the use of hypermedia based ebook shows maximum score and $\mathrm{N}$-gain is 0.87 and categorized very high, minimum score and $\mathrm{N}$-gain is 0.45 and categorized low and average score $\mathrm{N}$-gain is 0.66 and categorized high and standard deviation is 0.12 . The average score of integral calculus is 77.8 and categorized good and based on post-test result, 24 students $(80 \%)$ got 65 and passed the minimum mastery criteria.

The inferential analysis is conducted in two stages namely normality data test and t-test. The normality data test result shows significant value is bigger than alpha value $(0.073>0.05)$. This indicates that the data has normal distribution. The t-test shows that significant value is less than alpha value $(0.000<0.05)$. This indicates that $\mathrm{H} 0$ is rejected. It can be interpreted that there is a significant improvement on students integral calculus achievement after the use of hypermedia based ebook as instructional material. Taking the result of descriptive and inferential analyses result into account, it can be concluded that the use of hypermedia based ebook is effective to improve integral calculus achievement. 


\section{$5 \quad$ Findings}

Hypermedia based e-book is produced after being evaluated by experts. Based on the result of evaluation by media expert, it shows that hypermedia based ebook is calssified as very good. This is supported by the outlook, size, composition and usability of the hypermedia e-book. Good outlook of an ebook will improve text readibility, graphics or images, video, audio and animation. This indicates that outlook is important in designing hypermedia based e-book as instructional material. This is in line with Al-qassabi and Al-samarraie [15] who state that it is very important to apply instructional design theory to make multimedia-based ebooks. Meanwhile ebook size refers to font size, length of text and the number of images use, video, animation, audio. Ebook composition is color composition, text and video combination, text and animation combination and bypermedia combination.

Usability of hypermedia is viewed from the language use, access process, the media links and the consistency with the instructional objectives. This shows that students have the ability to read well when they use hypermedia based ebook. Similarly, Rvachew et al.[16] state that ebook for adult learner is designed to facilitate readers to improve their literacy skill. Moreover, Maxim and Maxim,[17] argue that mathematics can be taught using electronic publication that presents text and illustration, graphic animation and image, video with good delivery that can be tool of communication in learning. On the other hand, Maxim and Maxim,[17] reported that the use of ebook in the form of PDF has the ability to search important terminology fast in a document, cheaper and can be accessed through portable device. Glackin et al.[18] reported that using ebook in teaching significantly affects students' learning experience and improve literacy skill. Felvégi and Matthew [19] and Ebner and Prettenthaler [20] stated that using ebook with hypermedia components can improve students' potential behavior in learning. Moreover, a study by Kör et al.[21] shows that instructional materials in the form of PDF and video are used more often than animation and simulation. This is due to the nature of PDF and video that are easier to be prepared than animation, simulation and interactive media. Even though animation, simulation and interactive media are used in instruction, the percentage is low in comparison to PDF and video. This finding confirms that e-book with video and animation can be used in class.

This is because hypermedia based ebook not only enables students to study the calculus material but also interact with instructional material. As Binas et al.[6] state that ebook has its own characteristics such as providing interactive instructional material like bookmarks, quizzes and interactive lab exercises to enable students to study the material. Then Zhang-kennedy et al. [7] reported that interactive ebook affects acquisition, retention and transfer of knowledge and plays an important role to link between prior knowledge and new knowledge. Meanwhile according to Yildirim's [8], students learn more effectively using environmental based hypermedia. Yildirim et al.[9] argued that students' learning achievement after using hypemedia is better than traditional instruction.

In similar vein, Gonźalez et al.[10] stated that interactive e-book enables the text to be linked with various multimedia. Multimedia components include image, audio, 
video and animation. They further argued that developing interactive e-book can facilitate both lecturer and students in class. Through interactive e-book, students can access text, image, animation or video.

The calculus learning achievement improves significantly is due to the integration of video in e-books. Through video, students can study directly and observe the object closely that will improve their calculus achievement. According to Meij [13], video can motivate the students, improve understanding and performance. They went on saying that video can increase students' participation and material retention during class. According to Meij [13] video enables the students to finish the task and improve understanding and memory retention during class. Furthermore, video helps the students to do visual representation or enables them to construct information more accurately in their cognitive system [22].

This is in line with a study by Maxim and Maxim [17] on the appropriate book type between printed or electronic book? They found that the use of e-book in education gives positive effects. Subject like mathematics can use EPUB format that presents text and illustration, graphic animation and image, video with good delivery that serves as a tool of communication in class. Sanders [23] reported that in the USA, printed books have been replaced by e-books. The use of hypermedia-based e-book in integral calculus instruction is an interesting activity because the topics in integral calculus concerns indefinite integral concept, measuring the area under a curve with polygon method namely interior and exterior angle, measuring the area under a curve using Riemann sum. E-book will integrate image, audio, video and animation.

\section{Conclusion}

This research produced hypermedia based e-book to be used in integral calculus class. This ebook can be used to teach integral calculus at mathematics department. The instructional material in the form of hypermedia ebook has undergone formative evluation including expert evaluation, students evaluation, small group try out and large group try out. Based on the formative evaluation result, this hypermedia based ebook is appropriate to be used. Moreover, the result ofcalculus achievement test after using hypermedia based ebook shows that the ebook is significantly improve students' integral calculus achievement.

\section{$7 \quad$ References}

[1] B. Wibawa, B. P. Sitepu, and Awaludin, "Hypermedia-Based E-Book," Int. J. Multi Disipline Sci., pp. 14-22, 2018.

[2] Anonymous, PDF Reference, Second Edition. Boston: Wesley, 2000.

[3] S. Mishra and R. C. Sharma, Interactive multimedia in education and training. Idea Group Pub., 2005.

[4] A. H. Doering and M. D. Roblyer, "Integrating educational technology into teaching." Boston: Pearson, 2010.

[5] T. Vaughan, Multimedia: Making it work. McGraw-Hill, 2011. 
[6] M. Binas, P. Stancel, M. Novak, and M. Michalko, "Interactive eBook as a supporting tool for education process," in ICETA 2012 - 10th IEEE International Conference on Emerging eLearning Technologies and Applications, Proceedings, 2012. https://doi.org/10.1109/ iceta.2012.6418285

[7] L. Zhang-kennedy, Y. Abdelaziz, and S. Chiasson, "Cyberheroes: The Design and Evaluation of an Interactive Ebook to Educate Children about Online Privacy \$," Int. J. ChildComputer Interact., 2017. https://doi.org/10.1016/j.ijcci.2017.05.001

[8] Z. Yildirim, "Hypermedia as a cognitive tool: Student teachers' experiences in learning by doing,” J. Educ. Technol. Soc., vol. 8, no. 2, pp. 107-117, 2005.

[9] Z. Yildirim, M. Y. Ozden, and M. Aksu, "Comparison of Hypermedia Learning and Traditional Instruction on Knowledge Acauisition and Retention," no. October 2013, pp. 37-41, 2010.

[10] J. C. Gonźalez, J. L. Guzḿan, S. Dormido, and M. Berenguel, "Development of interactive books for control education,” in IFAC Proceedings Volumes (IFAC-PapersOnline), 2013. https://doi.org/10.3182/20130828-3-uk-2039.00038

[11] Awaludin, B. Wibawa, B. P. Sitepu, and M. Winarsih, "The Effect of Hypermedia-Based e-Book on Learning Achievement of Integral Calculus,” 2019. https://doi.org/10.4108/eai. 21-11-2018.2282043

[12] J. Brar and H. van der Meij, "Complex software training: Harnessing and optimizing video instruction," Comput. Human Behav., vol. 70, pp. 475-485, 2017. https://doi.org/10.1016/ j.chb.2017.01.014

[13] H. Van Der Meij, "Computers \& Education Reviews in instructional video," Comput. Educ., vol. 114, pp. 164-174, 2017. https://doi.org/10.1016/j.compedu.2017.07.002

[14] M. Bétrancourt and K. Benetos, "Why and when does instructional video facilitate learning? A commentary to the special issue 'developments and trends in learning with instructional video," Comput. Human Behav., vol. 89, pp. 471-475, 2018. https://doi.org/10. 1016/j.chb.2018.08.035

[15] H. Al-qassabi and H. Al-samarraie, "Applying Gagne's Nine Events in the Design of an Interactive eBook to Learn 3D Animation," vol. 3, no. 3, pp. 60-72, 2013.

[16] S. Rvachew, K. Rees, E. Carolan, and A. Nadig, "Improving emergent literacy with school-based shared reading: Paper versus ebooks,” Int. J. Child-Computer Interact., 2017. https://doi.org/10.1016/j.ijcci.2017.01.002

[17] A. Maxim and A. Maxim, "The role of e-books in reshaping the publishing industry," vol. 62, pp. 1046-1050, 2012. https://doi.org/10.1016/j.sbspro.2012.09.178

[18] B. C. Glackin, R. W. Rodenhiser, and B. Herzog, "A Library and the Disciplines: A Collaborative Project Assessing the Impact of eBooks and Mobile Devices on Student Learning,” J. Acad. Librariansh., vol. 40, no. 3-4, pp. 299-306, 2014. https://doi.org/10.1016/ j.acalib.2014.04.007

[19] E. Felvégi and K. I. Matthew, “eBooks and Literacy in K - 12 Schools," no. June 2013, pp. 37-41, 2012.

[20] M. Ebner and C. Prettenthaler, "Cloud-based service for eBooks using EPUB under the Aspect of Learning Analytics,” 2014. https://doi.org/10.1109/mcsoc.2014.25

[21] H. Kör, H. Aksoy, and H. Erbay, "Comparison of the Proficiency Level of the Course Materials (Animations, Videos, Simulations, E-Books) Used in Distance Education," Procedia - Soc. Behav. Sci., vol. 141, pp. 854-860, 2014. https://doi.org/10.1016/j.sbspro.2014. $\underline{05.150}$

[22] B. B. Boucheix, V. Hoogerheide, and J.-M. de Koning, "Developments and trends in learning with instructional video.," Comput. Human Behav., 2018. 
[23] M. Rice Sanders, B. McQuillan, and A. Carlson, "On Beyond E-Journals: Integrating EBooks, Streaming Video, and Digital Collections at the HELIN Library Consortium," Ser. Libr., vol. 62, no. 1-4, pp. 189-195, 2012. https://doi.org/10.1080/0361526x.2012.652920

\section{Authors}

Awaludin is a Doctorate student at Program Studi Teknologi Pendidikan Universitas Negeri Jakarta (UNJ) and working as Lecturer at Pendidikan Matematika Universitas Halu Oleo (UHO) awaludinrahman2016@gmail.com

Basuki Wibawa is a Lecturer at Program Studi Teknologi Pendidikan Universitas Negeri Jakarta (UNJ)

Murni Winarsih is a Lecturer at Program Studi Teknologi Pendidikan Universitas Negeri Jakarta (UNJ)

Article submitted 2020-01-24. Resubmitted 2020-02-17. Final acceptance 2020-02-17. Final version published as submitted by the authors. 